\title{
Isolation, purification and partial characterization of a glycoside from the Jamaican ball moss plant (Tillandsia recurvata L.)
}

\author{
Henry I. C. Lowe ${ }^{1,2,3}$, Charah T. Watson ${ }^{1,4}$, Simone Badal ${ }^{1,4^{*}}$, Ngeh J. Toyang ${ }^{2,3}$ Joseph Bryant $^{3}$ \\ ${ }^{1}$ Bio-Tech R \& D Institute, Kingston, Jamaica \\ ${ }^{2}$ Educational and Scientific Corporation, Wellington, USA \\ ${ }^{3}$ Institute of Human Virology, School of Medicine, University of Maryland, Baltimore, USA \\ ${ }^{4}$ Natural Products Institute, University of the West Indies, Mona, Jamaica \\ Email: ${ }^{*}$ simone.badal@uwimona.edu.jm
}

Received 15 May 2012; revised 21 June 2012; accepted 28 June 2012

\begin{abstract}
Initial isolation and characterization screens have been carried out on the Jamaican ball moss (Tillandsia recurvata L.) plant producing a novel complex glycosidic compound. This complex glycoside may be responsible for the promising anti-cancer and anti-inflammatory properties of this ball moss plant. A combination of supercritical fluid processing and chromatographic purification was used to produce the isolate. LC-MS analysis showed the presence of a compound with a molecular weight of $\sim 800$ and mass spectral (MS-MS and MS-MS-MS) data indicate that this compound may be a glycoside with a molecular mass of 1601.1 Da (negative ionization mode) and possibly contain up to two sialic acids, based on the doublycharged state of the molecule at neutral $\mathrm{pH}$ conditions. 2D-TOCSY NMR spectrum lends evidence to the presence of at least one likely amide to aliphatic proton correlation, indicating the presence of a sialic acid moiety. The main structure of this therapeutic compound appears similar to a soyasaponin.
\end{abstract}

Keywords: Jamaican Ball Moss; Tillandsia recurvata; Anti-Cancer; Anti-Inflammatory; LC-MS;

High-Resolution Mass Spectrometry; Total Correlation Spectroscopy (TOCSY)

\section{INTRODUCTION}

Cancer is a disease of de-regulated cell proliferation and is the leading cause of death in Jamaica [1] and the third leading cause of death worldwide [2-4] with an annual projection of 26 million new cases by 2030 of which 17 million deaths will occur [5]. Previous studies conducted on the Jamaican ball moss indicated that this plant exhibits

*Corresponding author. anti-inflammatory and anti-cancer potential against several cancer cell lines including; ex. PC-3 prostate cancer; Kaposi Sarcoma, B-cell lymphoma, breast cancer, and B-16 melanoma; [6]. The bioactivity of ball moss against these cell lines will prove useful in designing treatments against cancers of the prostate, connective tissue, immune system, breast and skin.

Prostate cancer is the most commonly diagnosed neoplasm in Jamaica [7] and is of significant concern among men of African descent [8] while breast cancer is the most common cancer among women in Jamaica and the second leading form of cancer worldwide [9]. The search for treatment associated with fewer side effects against these deadly diseases is on-going and so this research undertook investigations to determine the active ingredient in ball moss possibly responsible for the plant's anti-cancer and anti-inflammatory properties

Tillandsia recurvata L., commonly known as ball moss is a flowering plant (not a true moss) that grows upon larger host plants in Jamaica. Older plants develop multiple ramets or clones which form a spherical tussock and can range in size from a golf ball to a basketball, hence the common name "ball moss" [10]. It grows well in areas with low light, minimal airflow and high humidity, which is commonly provided by southern shade trees as well as electrical poles. It is not a parasite like mistletoe, but an epiphyte weed like its relative Spanish moss.

The genus Tillandsia is a group of epiphytic plants with approximately 500 species that belong to the subfamily Tillandsioideae and the family Bromliaceae. While research on the Tillandsia genus remains limited, Tillandsiausneoides, commonly known as "Spanish moss," is the most extensively studied species [11-13]. There are no reports of traditional use of this species; however, research has shown its potential medicinal value in treating hypoglycemia, rheumatoid arthritis and liver infections [12]. In Brazil, its anti-inflammatory activity is sometimes 
used against rheumatism, ulcers, and hemorrhoids [14,15]. In addition, research has identified several phytochemicals from the plant and these include; cycloartanetriterpenoids, pentacyclictriterpenes, sterols, and flavonoids [16]. Previous phytochemical studies showed the presence of hydroperoxyclycloartanes, a dicinnamate, flavanone, and a caffeic acid ester from the whole plant extracts [16,17]. The current paper describes the chemical and spectral characterization of a compound partially characterized from Tillandsia recurvata $\mathrm{L}$.

\section{MATERIALS AND METHODS}

\subsection{Plant Material}

The whole $T$. recurvata plant was collected from trees and electricity poles in Kingston, Jamaica. A voucher specimen of the plant was identified at the Institute of Jamaica Herbarium where it is deposited with Accession Number: IJ 3411. The collected plant material was air dried under shade, pulverized into powder, and stored at $4^{\circ} \mathrm{C}$.

\subsection{General Experimental Procedures}

Supercritical fluid extractions were conducted using Aphios bench scale super fluids ${ }^{\mathrm{TM}}$, CXP unit $(127 \mathrm{ml}$ extraction column (rated for 10,000 psig) and a $50 \mathrm{ml}$ chromatographic column (rated for 10,000 psig)). HPLC (Agilent 1100, IQ-0001, Santa Clara, CA) was connected to a UV/VIS detector using a Phenomenex Luna C18 (2), 4.6 $\mathrm{mm} \times 15 \mathrm{~cm}$ column at wavelengths of 210, 254, and 280 . Mass spectra of extracts were acquired using an Agilent Tof equipped with an electrospray ionization (ESI) source. The mobile phase was a binary system consisting of Solvent A: $10 \mathrm{mM}$ ammonium acetate in 75\% HPLC grade water/25\% acetonitrile and Solvent B: 100\% acetonitrile. The injection volume was $5 \mu \mathrm{l}$ and the flow rate was 0.2 $\mathrm{ml} / \mathrm{min}$. All chemicals used were of analytical grade.

Proton NMR experiments were performed using a Varian $600 \mathrm{MHz}{ }^{1} \mathrm{H}$ NMR system with tetramethylsilane (TMS) as an internal standard. The JEM 03-25 sample was dissolved in $200 \mu$ l deuterated methanol (99.9\% from Cambridge Isotopes) and delivered into a $3 \mathrm{~mm}$ NMR tube for analysis at $25^{\circ} \mathrm{C}$. Two-dimensional Total Correlation Spectroscopy (TOCSY, 2D-NMR) was determined at $25^{\circ} \mathrm{C}$ using a Varian $750 \mathrm{MHz}$ proton-proton NMR system. Samples were dissolved in deuterated methanol.

\subsection{Extraction and Isolation}

Ball moss biomass (28 g) was subjected to supercritical fluid extractions ((70\% $\mathrm{CO}_{2}: 30 \%$ methanol) to yield 7 fractions (JEM 01-JEM 07)). Bio-guided assays showed that 3 fractions (JEM 03-JEM 05) were most bioactive (killed $99.1 \%$ of cells at $0.07-70 \mu \mathrm{g} / \mathrm{ml}$ ) against B-16 cancer cells and non-toxic to experimental rat models. Purity of the fractions was analyzed using gradient RPHPLC-PDA (acidic acetonitrile: water mobile phase at $30^{\circ} \mathrm{C}$ at a flow rate of $1.0 \mathrm{ml} / \mathrm{min}$ ) at 205 and $280 \mathrm{~nm}$ wavelengths which indicated that the 3 former fractions displayed similar chemical profiles. Being the most bioactive and displaying the least number of peaks, JEM 03 was then further subjected to preparatory scale C-18 HPLC column (10\% ACN to 100\% ACN for 60 minutes at $1.5 \mathrm{ml} / \mathrm{min}$ ) yielding 50 fractions of which JEM 03-25 was the most bioactive.

\subsection{LC-MS Analysis of Extracts}

Further fragmentation analyses on JEM 03-25 were conducted by LC-MS-MS and LC-MS-MS-MS. An Agilent 1100 HPLC system equipped with an ion trap-mass spectrometer 6340 was used. For MS-MS analysis, sample fragmentation was accomplished by CID. Mobile phase consisted of $25 \mathrm{mM}$ ammonium acetate in 50\% acetonitrile. The sample buffer was prepared by adding $3.85 \mathrm{~g}$ ammonium acetate to $1 \mathrm{~L}$ HPLC water to produce $50 \mathrm{mM}$ ammonium acetate. A $10 \mathrm{~mL}$ quantity of $50 \mathrm{mM}$ ammonium acetate was then added to $10 \mathrm{~mL}$ of acetonitrile. Samples were diluted 1:2 (10 $\mu$ l sample in $20 \mu \mathrm{l}$ buffer) in mobile phase. Flow was maintained at $0.25 \mu \mathrm{l} / \mathrm{min}$ by the infusion pump. Detection was by ion trap (IT) ITMS-MS in both positive and negative ionization modes, with additional fragmentation modes (MS3 and MS4, ETD) applied to yield maximum fragmentation results. Total ion chromatograms were analyzed by the Analyst $^{\mathrm{TM}}$ software in order to obtain the respective mass spectra across the specified time ranges.

\section{RESULTS AND DISCUSSION}

Polarity-guided fractionation experiments were conducted on the dried JEM biomass utilizing a bioassay-guided fractionation approach employing supercritical fluid technology. These experiments were selected since the use of conventional organic solvents is not always ideal for the extraction of phytochemicals. This is due to the difficulty involved in separating the compounds of interest from the solvent which can result in masked bioactivity [15]. Fractionation of the JEM biomass was carried out in two steps. In the first step, the biomass was disrupted by exposing it to a fluid at or near its supercritical pressure. In the second step, the disrupted biomass interacted with the supercritical fluid(s) in several successive steps at different solvation conditions used for each fractionation. $\mathrm{CO}_{2}$ exposed to specific conditions (204 atm and $40^{\circ} \mathrm{C}$ ), behaved like a non-polar organic solvent and its selectivity was enhanced by the use of polar entrainers or co-solvents such as ethanol or methanol [15], While the solvation conditions to fractionate the active constituents can vary 
from $100 \%$ carbon dioxide $\left(\mathrm{CO}_{2}\right)$ to $100 \%$ methanol $\left(\mathrm{CH}_{3} \mathrm{OH}\right)$, the optimum levels were found to be $70 \%$ carbon dioxide and $30 \%$ methanol. The final yield of the most effective concentrated JEM biomass fraction (JEM 03-25) was estimated at $0.068 \%$ which compares well with potent anti-cancer compounds Taxol ${ }^{\circledR}$ or paclitaxel $(0.02 \%-0.05 \%)$ isolated from the Taxus media Yew tree [18].

Detection of peaks was performed by HPLC-PDA (photo diode array detector) with UV absorbance at 210 $\mathrm{nm}, 254 \mathrm{~nm}$, and $280 \mathrm{~nm}$, in addition to the in-line detection by MS. Figure 1 shows that sample JEM 03-25 had only three significant peaks at $210 \mathrm{~nm}$; of these, the peak at 14 minutes was also detectable at $254 \mathrm{~nm}$ and $280 \mathrm{~nm}$, and the doublet at ca. 20 minutes that did not absorb at either $254 \mathrm{~nm}$ or $280 \mathrm{~nm}$.

Analysis of these samples using in-line high-resolution mass spectrometry by electrospray ionization (ESI) with time-of-flight in both positive and negative modes resulted in the detection of a series of masses ranging from $133 \mathrm{~m} / \mathrm{z}$ to $134 \mathrm{~m} / \mathrm{z}$. Of major interest was the doublet in
JEM 03-25 which was eluted between 20 and 22 minutes $(210 \mathrm{~nm})$ to yield strong signals at 809.5 and $821.5 \mathrm{~m} / \mathrm{z}$ in the positive mode and $808.0 \mathrm{~m} / \mathrm{z}$ in the negative mode. No obvious mass signal was detected for the peak that was eluted at 14 minutes $(210 \mathrm{~nm}, 254 \mathrm{~nm}$, or $280 \mathrm{~nm})$. These results confirm that JEM 03-25 contained the fewest number of components. Since JEM 03-25 was the most bioactive fraction and the doublet observed was eluted between 20 and 22 minutes $(210 \mathrm{~nm})$ which made it unique, further fragmentation analyses were conducted on this compound (peak) by LC-MS and LC-MS-MS-MS.

The ion trap survey mass spectrum was extracted and de-convoluted to yield the masses provided in Table 1. Results show that the main species found in sample JEM 03-25 displayed a molecular mass of 1601.1 in negative ionization mode. While the major peak detected at $\mathrm{m} / \mathrm{z}$ 1617.0 represented the oxidized form of the molecule, major peaks at $\mathrm{m} / \mathrm{z} 800.7$ and 808.2 represented the main species and its oxidized doubly-charged form. Positive ion mode analysis yielded similar results, although the molecule was detected with several adducts being present

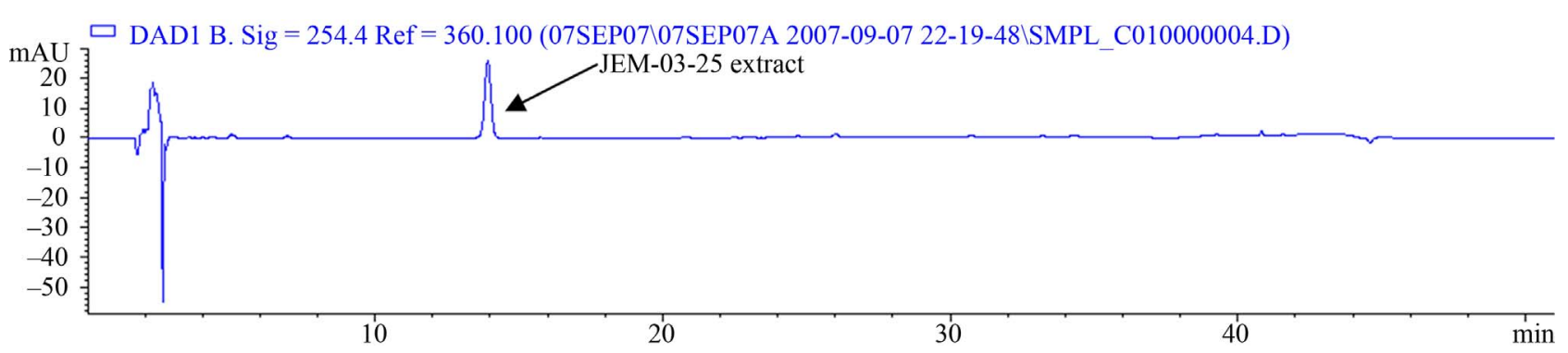

(a)

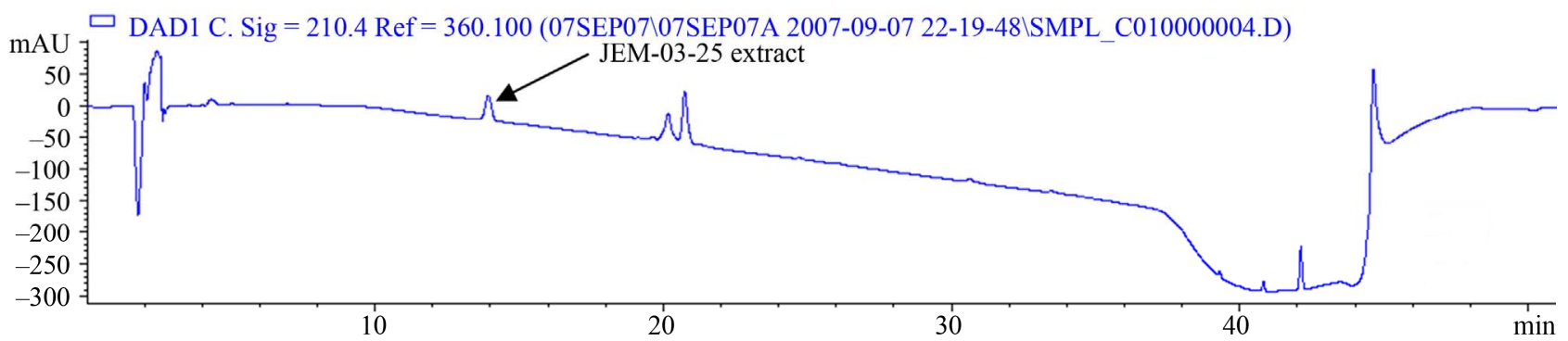

(b)

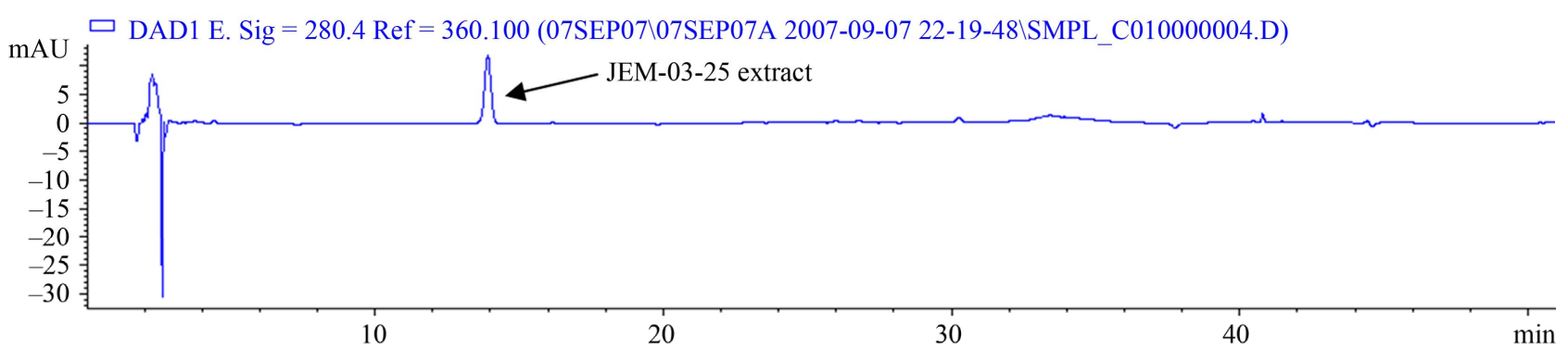

(c)

Figure 1. RP-HPLC Chromatograms of JEM 03-25 extract. (a) Detection at $254 \mathrm{~nm}$; (b) Detection at $210 \mathrm{~nm}$; and (c) Detection at $280 \mathrm{~nm}$. 
(see Table 1). We conclude therefore that the molecule is a glycoside with a molecular mass of 1601.1 Da (negative ion mode), containing up to two sialic acids, based on its doubly charged state under neutral $\mathrm{pH}$ conditions. In addition, since the molecule was also found to carry two positive charges, there may be two amines present within its structure. Database searches did not reveal any known molecules or dimmers with these characteristics.

Results from the fragmentation of the major peaks by both collision-induced dissociation (CID) and electron transfer dissociation (ETD) obtained in negative ion mode can be seen in Table 2. A similar fragment spectrum was obtained from fragments generated from both the single and doubly-charged precursors, indicating that both precursors were identical. In addition, fragmentation of oxidized precursors also yielded oxidized fragments. Fragmentation performed in positive ion mode yielded no detectable unique ions. Based on the fragmentation spectra, the analyte appeared to contain at least one (perhaps two) sialic acid moieties which could be $\mathrm{N}$-acetylneuraminic acid (Neu5Ac) and N-glycosylneuraminic acid (Neu5Gc). This conclusion is based on the characteristic mass difference of 292 daltons found between the fragment masses at 796.5 and 1088.8. Other fragment masses are less facile to match with known structures, but the mass differences may be consistent with a polysaccharide structure. HPLC and mass spectrometry results appear to exclude the presence of any aromatic structures. Monosaccharide content analysis or chemical derivatization along with ${ }^{1} \mathrm{H}$ and ${ }^{13} \mathrm{C}-$ NMR of the molecule may yield further information. Based on gradient and isocratic HPLC analyses with detection by UV-PDA and evaporative light scattering detector (ELSD), JEM 03-25 appeared to have a UV spectra maximum at $193.7 \mathrm{~nm}$ and is a weak absorber suggesting the absence of aromatic groups (Figure 2). No known existing molecules with this spectra and molecular weights were identified; therefore we can conclude that the molecule could be novel.

Table 1. Masses detected by ion trap mass spectrometry (MS).

\begin{tabular}{|c|c|c|c|c|}
\hline $\begin{array}{c}\text { Ionization } \\
\text { mode }\end{array}$ & $\begin{array}{c}\text { Detected } \\
\text { mass }\end{array}$ & $\begin{array}{l}\text { Charge } \\
\text { state }\end{array}$ & $\begin{array}{c}\text { Molecular } \\
\text { mass }\end{array}$ & Notes \\
\hline Negative & 1616.0 & -1 & 1617.0 & oxidized molecule ${ }^{\mathrm{i}}$ \\
\hline Negative & 1600.1 & -1 & 1601.1 & native molecule \\
\hline Negative & 808.2 & -2 & 1616.2 & oxidized molecule \\
\hline Negative & 800.7 & -2 & 1601.4 & native molecule \\
\hline Positive & 1618.0 & +1 & 1617.0 & $\begin{array}{c}\text { oxidized molecule } \\
\text { oxidized molecule }^{+}\end{array}$ \\
\hline Positive & 1635.1 & +1 & 1634.1 & amine \\
\hline Positive & 809.7 & +2 & 1617.4 & $\begin{array}{l}\text { oxidized molecule } \\
\text { oxidized molecule }^{+}\end{array}$ \\
\hline Positive & 818.0 & +2 & 1635.0 & amine \\
\hline
\end{tabular}

Two-dimensional $750 \mathrm{MHz}$ proton-proton (TOCSY) was used to determine correlations for protons in the spin systems (e.g., sugar rings or chains of coupled aliphatic protons). Based on this, JEM 03-25 appears to be a highly aliphatic compound possibly consisting the following; 1 to 3 sugar rings, several aliphatic rings and a hydrocarbon chain(s). There are at least six methyl $\left(\mathrm{CH}_{3}\right)$ groups and on the order of $10 \mathrm{CH}_{2}$ and $\mathrm{CH}$ groups. There is also evidence of at least one likely amide to aliphatic proton correlation (Figure 3), lending credence to the MS-based hypothesis that a sialic acid moiety may be present in the molecule. Under the current sample conditions, exchangeable protons are expected to be weak and difficult to observe. Next, a proton NMR of JEM 03-25 was assessed for structural characterization. Figure 4 shows the full spectrum with major peak annotations. The spectrum indicates the presence of impurities. Table $\mathbf{3}$ is a list of the relative integrals from Figure 4. The proton at $7.97 \mathrm{ppm}$ is assumed to be one proton, and all other integrals are relative to this peak.

Finally, JEM 03-25 was analyzed using 2D-TOCSY, an experiment that showed correlations for protons in a given spin system. In theory, TOCSY correlates connectivity of protons throughout an entire spin system and is a very useful tool for characterizing natural products. Figure 5 is an expansion of the $\mathrm{CH}_{2}-\mathrm{CH}_{3}$ region of the TOCSY spectrum. It features a relatively large number of coupled $\mathrm{CH}_{2}$ and $\mathrm{CH}_{3}$ protons, these types of correlations indicate that the molecule is likely one that has multiple aliphatic rings and/or aliphatic chains. Due to the relatively complex nature of the spectrum, it is very difficult to obtain definitive numbers of $\mathrm{CH}_{2}$ and $\mathrm{CH}_{3}$ groups, but there are certainly enough to suggest a molecular weight of 800 - 900 (or even 1600 if it is some sort of dimer). Further 2D experiments will allow for more specific information to be obtained.

Figure 6 is a density display of the entire TOCSY spectrum of JEM 03-25. The peaks between $\sim 6.5$ and 8.6 ppm are from aromatic and $\mathrm{NH}, \mathrm{NH}_{2}$ protons. The circled peak shows a weak, but clearly present, correlation between what is likely an amide proton and a $\mathrm{CH}_{2}$ (insert chemical shift relating to this group) group. This agrees with the postulate that there could be a sialic acid moiety in the molecule. This peak is very weak given the sample conditions as amide protons would readily exchange with deuterons in the solvent. There are also a number of aromatic protons; however, they do not appear to show correlations to aliphatic protons. This is consistent with the idea that there is a "contaminant" in the sample, which may be from the relatively low molecular weight plasticizer.

HPLC analysis in Figure 1 shows that sample JEM 0325 appeared to contain the fewest number of components based on one peak which eluted at ca. 14 minutes within the gradient and then a doublet which eluted between 20 
Table 2. Negative ion mode fragmentation (MS-MS).

\begin{tabular}{|c|c|c|}
\hline Parent/precursor mass & 808.2 & 1616.0 \\
\hline Fragment masses & mass/charge & mass/charge \\
\hline & 385.5 & 692.5 \\
\hline & 386.4 & 720.6 \\
\hline & 409.5 & 721.5 \\
\hline & 701.6 & 765.3 \\
\hline & 737.2 & 795.6 \\
\hline & 744.1 & 796.6 \\
\hline & 770.1 & 1088.7 \\
\hline & 772.5 & 1089.8 \\
\hline & 786.2 & 1090.7 \\
\hline & 795.6 & 1272.8 \\
\hline & 796.5 & 1273.8 \\
\hline & 819.7 & 1287.3 \\
\hline & 1088.8 & 1297.5 \\
\hline & 1089.8 & 1372.3 \\
\hline & 1229.8 & 1373.2 \\
\hline & 1230.8 & 1374.1 \\
\hline & 1231.8 & 1382.3 \\
\hline & 1400.2 & 1400.1 \\
\hline & 1401 & 1401 \\
\hline & & 1402 \\
\hline & & 1403 \\
\hline & & 1414.1 \\
\hline & & 1415 \\
\hline & & 1475 \\
\hline & & 1476 \\
\hline & & 1477.1 \\
\hline & & 1489.1 \\
\hline & & 1541.2 \\
\hline & & 1542.2 \\
\hline & & 1543.1 \\
\hline & & 1597.9 \\
\hline & & 1599.3 \\
\hline
\end{tabular}

Table 3. NMR integration list.

\begin{tabular}{ccccc}
\hline $\mathbf{N}$ & Start ppm & End ppm & Absolute. Int. Normalized Int. \\
\hline 1 & 7.9905 & 7.9471 & 225.83 & 1.00 \\
2 & 7.9038 & 7.8581 & 394.36 & 1.75 \\
3 & 7.8262 & 7.7668 & 350.43 & 1.55 \\
4 & 7.6459 & 7.5866 & 328.41 & 1.45 \\
5 & 7.5730 & 7.5159 & 266.47 & 1.18 \\
6 & 7.3083 & 7.2398 & 625.47 & 2.77 \\
7 & 7.1189 & 6.9842 & 1260.71 & 5.58 \\
\hline
\end{tabular}

and 22 minutes. The doublet seen between 20 and 22 minutes for JEM 03-25 contained species with $\mathrm{m} / \mathrm{z}$ values of 808.0 in negative ionization mode and 809.5 and 821.5 in positive ionization mode. No ionizable species were detected for the peak eluting at 14 minutes.

The proposed structure of the therapeutic principle in the JEM 03-25 extract responsible for its anti-cancer and anti-inflammatory activities appears to be similar to a soyasaponin. Soyasaponins are major phytochemicals present in legume seeds [19]. The basic structure of soyasaponins is an oleanene-type triterpenoidaglycone with one or more polysaccharide chains attached, resulting in the amphiphilic nature of the molecules. Soyasaponins have been shown to have a variety of health-promoting properties including anti-viral activities [20,21] and anti-carcinogenic [22,23], plasma cholesterol lowering [24,25], and hepatoprotective effects [26,27].

A schematic representation of the proposed structure of this Soyasapoinintype compound is presented in Figure 7 . While this structure is highly speculative at this point, chemistry data does point to the potential class of the molecule of interest. The sugar rings shown here could be of a sialic acid type; however, the exact number of sugars cannot be determined at this time. Alternatively, there could be an aliphatic chain(s), although closed rings are suspected.

\section{CONCLUSION}

A 2D-TOCSY spectrum was generated from the JEM 03-25 fraction despite the low concentration for NMR studies. From this spectrum, the molecule of interest appears to be a highly aliphatic compound possibly consisting of 1 - 3 sugar rings, several aliphatic rings, and a hydrocarbon chain(s). There are at least six methyl $\left(\mathrm{CH}_{3}\right)$ groups and on the order of $10 \mathrm{CH}_{2}$ and $\mathrm{CH}$ groups. There is evidence of at least one likely amide to aliphatic proton correlation, lending credence to the MS-based hypothesis that a sialic acid moiety may be present in the molecule. Although there

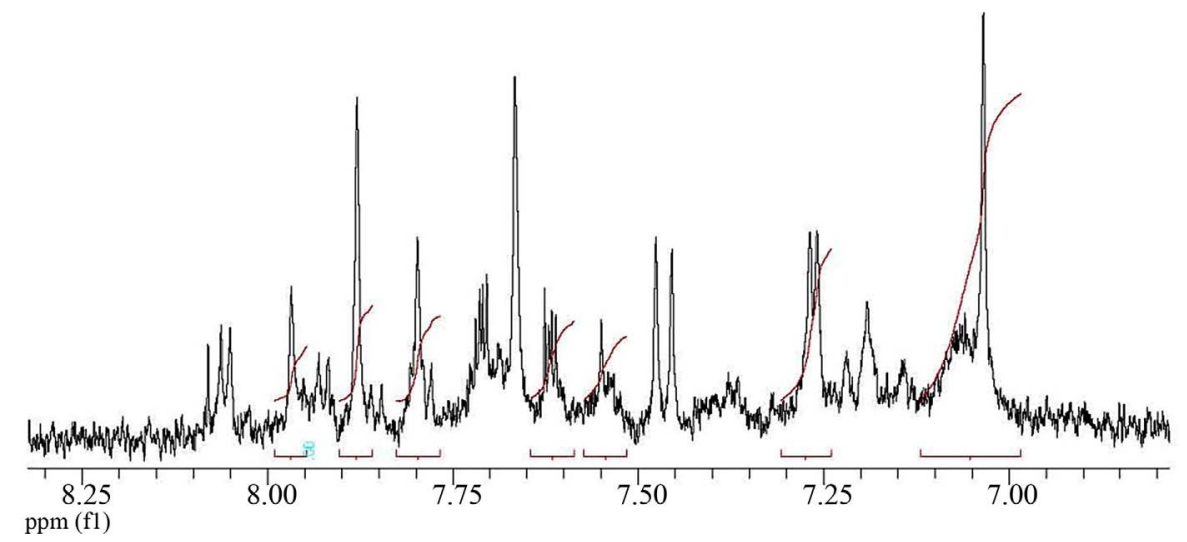

Figure 2. Aromatic region of $600 \mathrm{MHz}$ proton spectrum of JEM 03-25. 


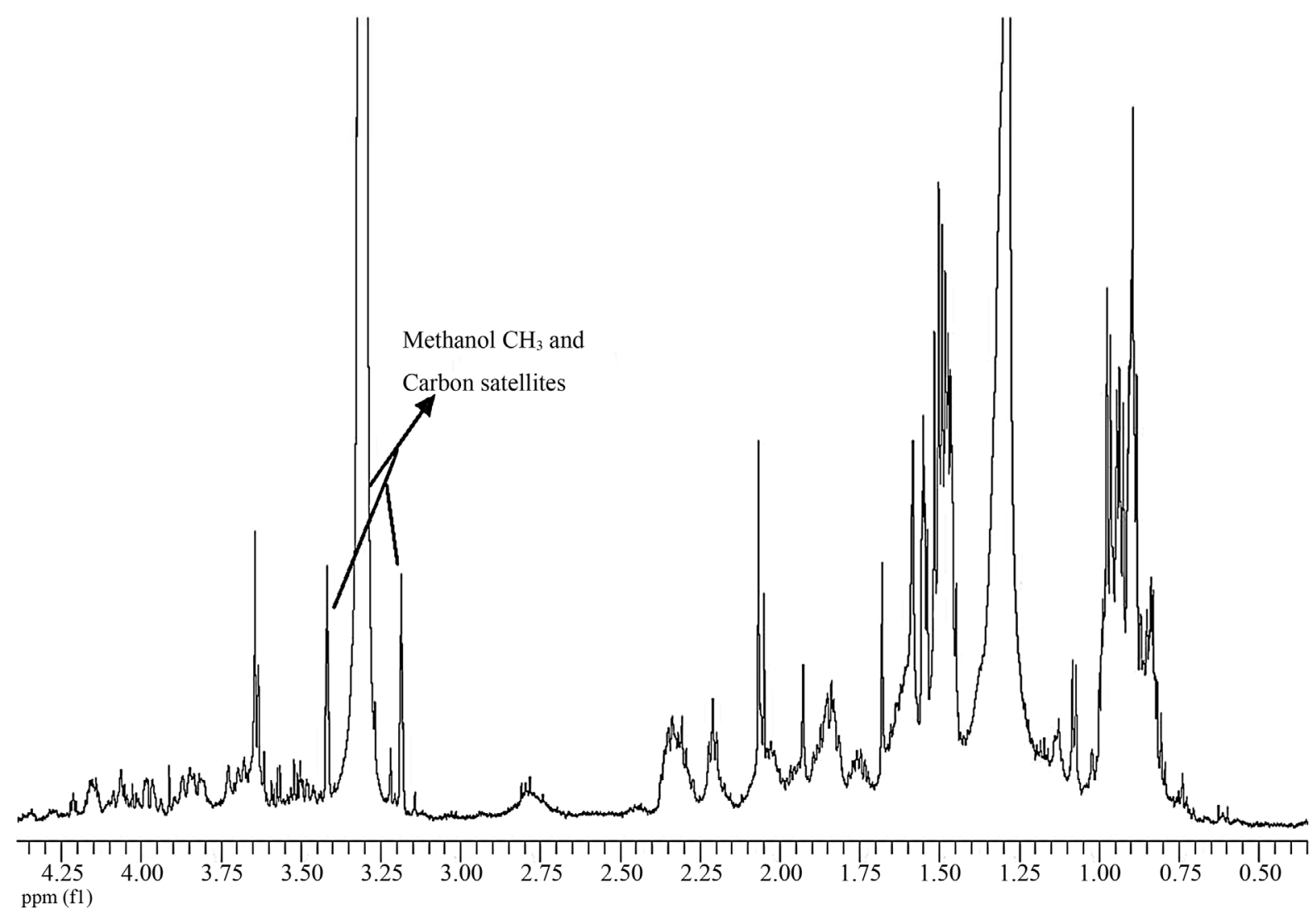

Figure 3. Aliphatic region of $600 \mathrm{MHz}$ proton spectrum of JEM 03-25.

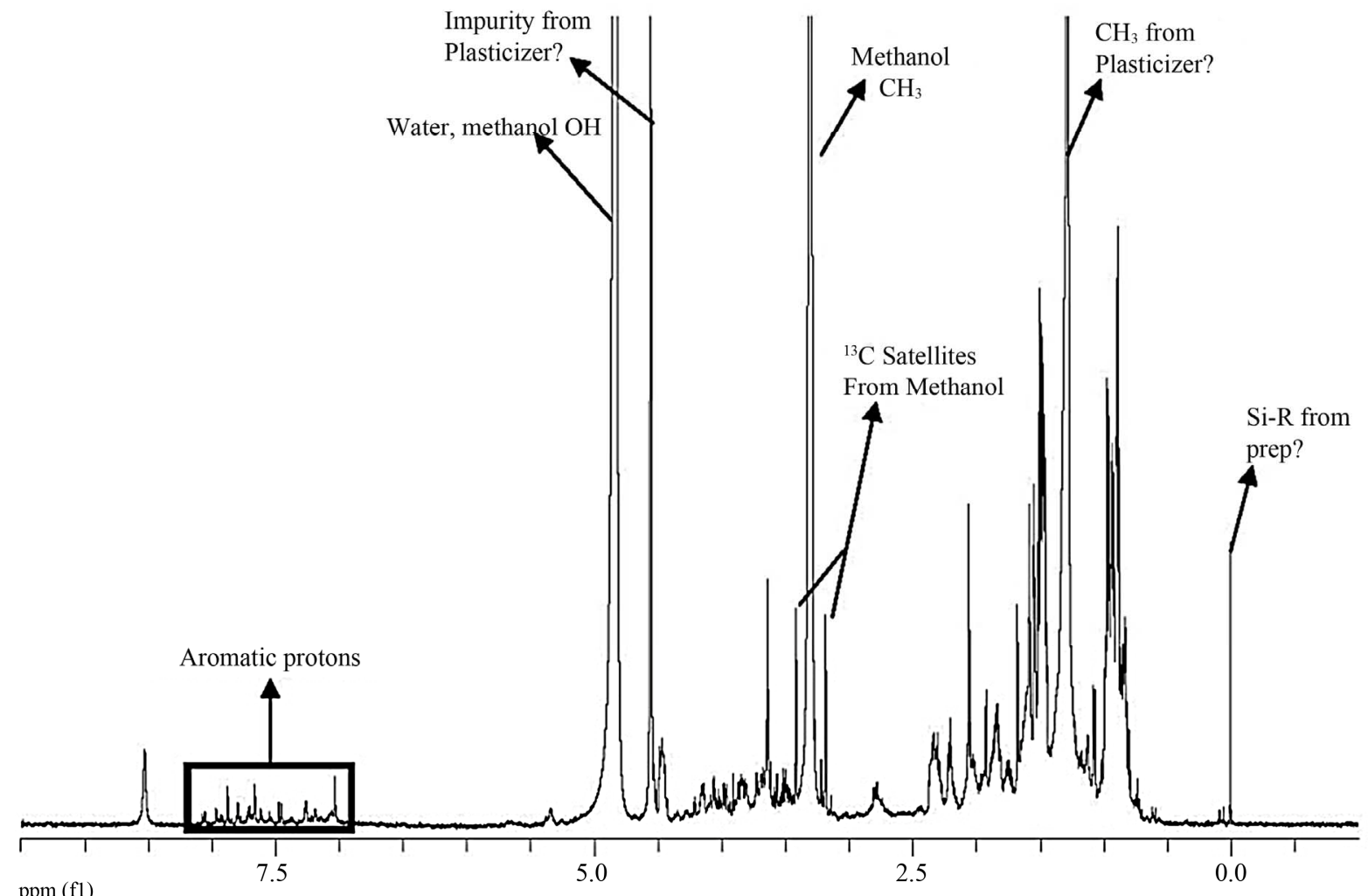

Figure 4. $600 \mathrm{MHZ}$ proton spectrum of JEM 03-25. 


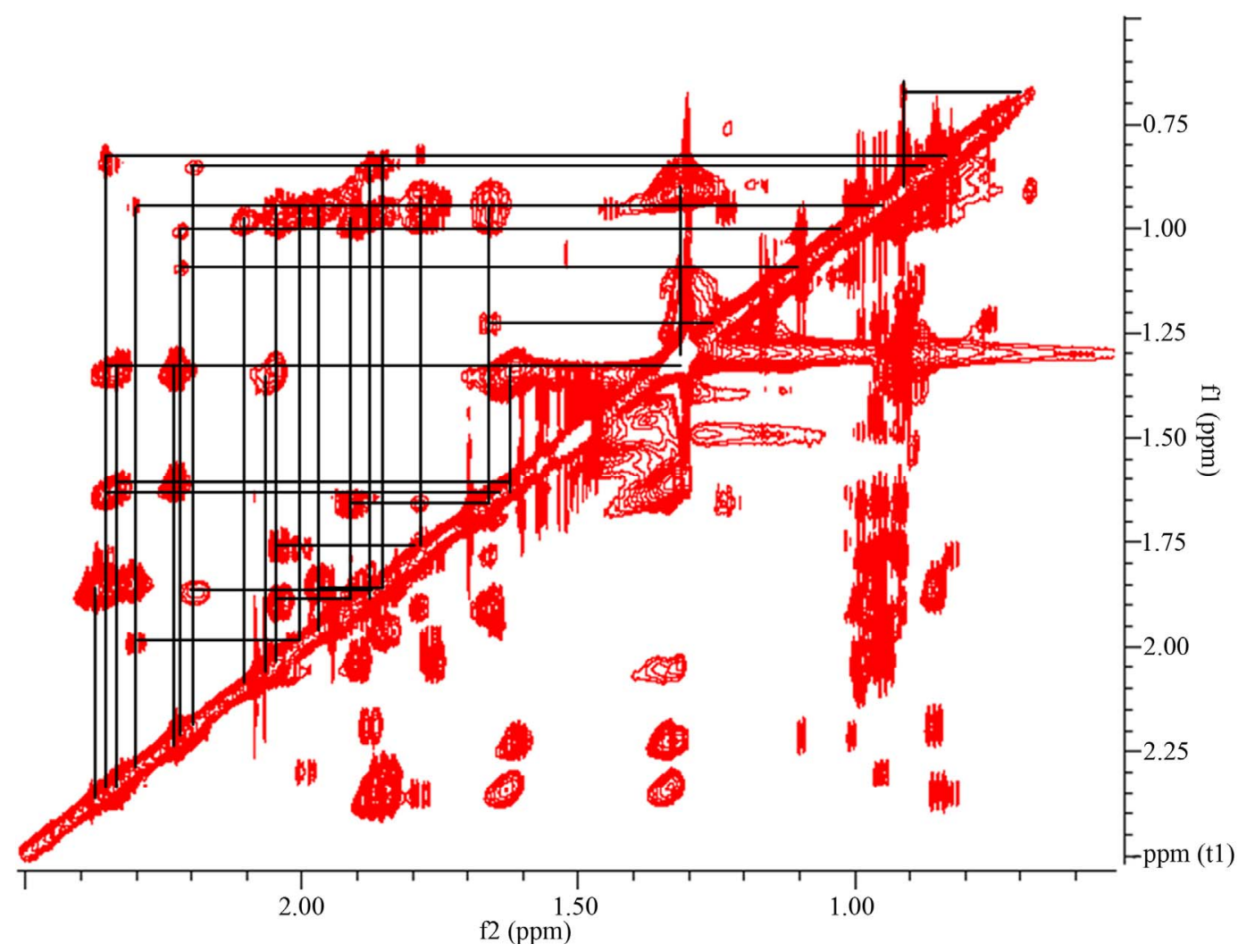

Figure 5. Expansion of the CH2-CH3 region of the TOCSY spectrum.

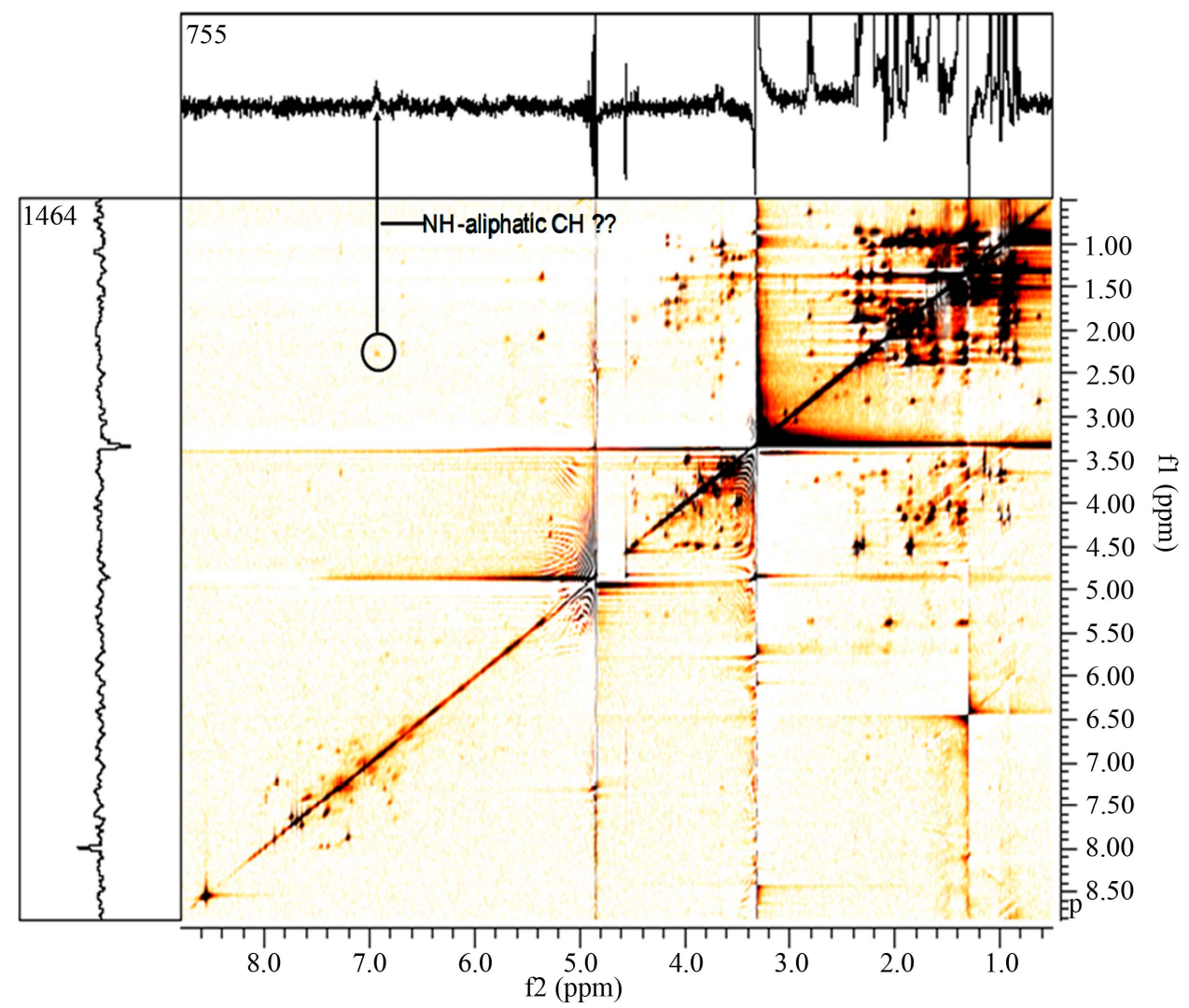

Figure 6. Density display of the entire TOCSY spectrum of JEM 03-25. 


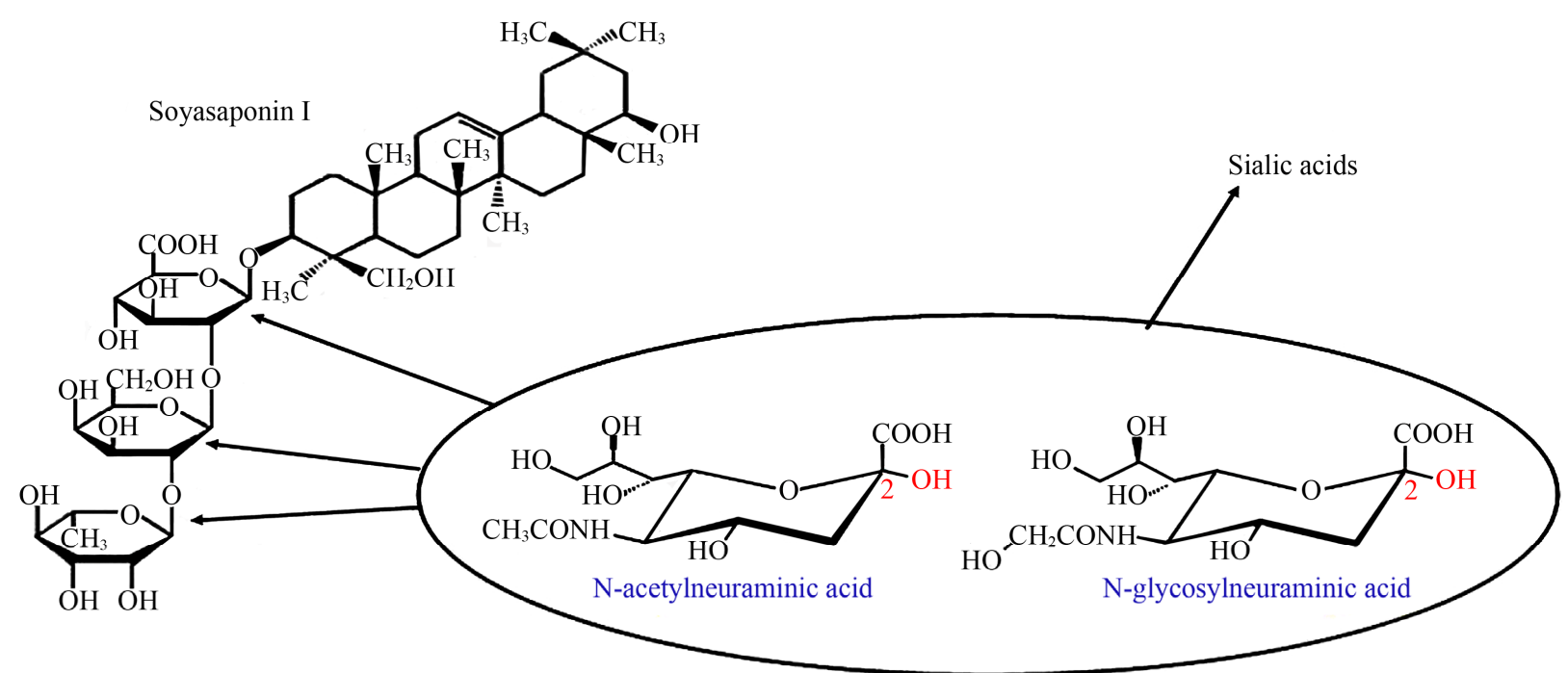

Figure 7. Structural moieties of JEM 03-25 extracted from Tillandsia recurvata L., (Jamaican ball moss).

are peaks and TOCSY correlations in the aromatic region, these could be as a result of impurity in the sample. Further characterization of this novel isolate from the Jamaican ball moss might be useful as the search for potent anticancer and anti-inflammatory agents continue.

\section{ACKNOWLEDGEMENTS}

We would like to thank Mr. Keron Campbell from Institute of Jamaica Herbarium for identification of the plant and Ms. Keneisha Cooper for her help in the plant collection.

\section{REFERENCES}

[1] Ministry of Health (2005) Epidemiological profile of selected health conditions and services in Jamaica 19902002. Vital Statistics Report 2002, Registrar General's Department.

[2] American Cancer Society (2007) Global cancer facts and figures 2007. American Cancer Society, Atlanta. http://www.cancer.org/acs/groups/content/@nho/docume nts/document/globalfactsandfigures2007rev2p.pdf

[3] Reinberg, S. (2007) Cancer killed almost 8 million worldwide in 2007.

http://health.usnews.com/usnews/health/healthday/07121 7/cancer-killed-almost-8-million-worldwide-in-2007.htm

[4] World Health Organization (2006) Cancer. http://www.who.int/mediacentre/factsheets/fs297/en/

[5] Boyle, P. and Levin, B. (2008) World Cancer Report, 2008.

http://apps.who.int/bookorders/anglais/detart1.jsp?sesslan =1\&codlan=1\&codcol=76\&codcch=26Lyon

[6] Lowe, H. (2010) Anti-tumor and anti-inflmmatory extracts of plant biomass and their uses. US 7713556B2, Jamaica, 1-14.

[7] Jackson, M., Walker, S., Simpson, C., et al. (2009) Are food patterns associated with prostate cancer in Jamaican men: A preliminary report. Infectious Agents and Cancer, 4, S1-S5. doi:10.1186/1750-9378-4-S1-S5

[8] Odedina, F., Akinremi, T., Chinegwundoh, F., et al. (2009) Prostate cancer disparities in Black men of African descent: A comparative literature review of prostate cancer burden among Black men in the United States, Caribbean, United Kingdom, and West Africa. Infectious Agents and Cancer, 4, S1-S2. doi:10.1186/1750-9378-4-S1-S2

[9] National Cancer Institute (2007) Revision history of the SEER cancer statistics review, 1975-2007. http://seer.cancer.gov/csr/1975_2007/revisions.html

[10] Benzing, D. (1980) The biology of the bromeliads. Mad River Press, Eureka.

[11] Andrighetti-Fröhner, C.R., Sincero, T.C., Da Silva, A.C., et al. (2005) Antiviral evaluation of plants from Brazilian Tropical Forest. Fitoterapia, 76, 374-378. doi:10.1016/j.fitote.2005.03.010

[12] Witherup, K., McLaughlin, J., Judd, R., et al. (1995) Identification of 3-hydroxy-3-methylglutaric acid (HMG) as a hypoglycemic principle of Spanish moss (Tillandsia usneoides). Journal of Natural Products, 58, 1285-1290. doi:10.1021/np50122a023

[13] Bermudez, G. and Pignata, M. (2011) Antioxidant response of three Tillandsia species transplanted to urban, agricultural, and industrial areas. Archives of Environmental Contamination and Toxicology, 61, 401-413. doi:10.1007/s00244-010-9642-y

[14] Agra, M., Silva, K., Basilio, I., et al. (2008) Survey of medicinal plants used in the region Northeast of Brazil. Brazilian Journal of Pharmacognosy, 18.

[15] Castor, T., Chikarmane, H., Hong, G., et al. (1998) Methods for fractionation of biologically-derived materials. US Patent \#5854064.

[16] De Queiroga, M., Andrade, L., Florencio, K., et al. (2004) Chemical constituents from Tillandsia recurvata. Fi- 
toterapia, 75, 423-425. doi:10.1016/j.fitote.2004.01.003

[17] Cabrera, G. and Selde, A. (1995) Hydroperoxycycloartanes from Tillandsia recurvata. Journal of Natural Products, 58, 1920-1924. doi:10.1021/np50126a020

[18] Lowe, H. (2008) Anti-tumor and anti-inflammatory extracts of plant biomass and their uses. US Patent \#7713556.

[19] Price, K., Curl, C. and Fenwick, G. (1986) The saponin content and sapogenol composition of the seed of 13 varieties of legume. Journal of the Science of Food and Agriculture, 37, 1185-1191. doi:10.1002/jsfa.2740371206

[20] Nakashima, H., Okudo, K., Honda, Y., et al. (1989) Inhibitory effect of glycosides like saponins from soybean on the infectivity of HIV in vitro. AIDS, 3, 655-658.

[21] Hayshi, K., Hayshi, H., Hiraoka, N., et al. (1997) Inhibitory activity of soyasaponin II on virus replication in vitro. Planta Medica, 63, 102-105. doi:10.1055/s-2006-957622

[22] Rao, A.V. and Sung, M.K. (1995) Saponins are anticarcinogens. Journal of Nutrition, 125, 717S-724S.

[23] Konoshima, T. (1996) Anti-tumor promoting activities of triterpenoid glycosides; cancer chemoprevention by saponins. Advances in Experimental Medicine and Biology, 404, 87-100.

[24] Oakenfull, D. and Sidhu, G. (1990) Could saponins be a useful treatment for hypercholesterolemia? European Journal of Clinical Nutrition, 44, 79-88.

[25] Potter, S.M. (1995) Overview of proposed mechanisms for the hypercholesterolemic effect of soy. Journal of Nutrition, 125, 606S-611S.

[26] Miyao, H., Arao, T., Udayama, M., et al. (1998) Kaikasaponin III and soyasaponin I, major triterpenesaponins of Abruscantoniensis, act on GOT and GPT; influence on transaminase elevation of rat liver cells concomitantly exposed to CCl4 for one hour. Planta Medica, 64, 5-7. doi:10.1055/s-2006-957355

[27] Kinjo, J., Imagire, M., Udayama, M., et al. (1998) Structure-hepatoprotective relationships study of soyasaponins I-IV having soyasapogenol B as aglycone. Planta Medica, 64, 233-236. doi:10.1055/s-2006-957416 